\section{INVESTIGATIONS OF THE REINFORCEMENT AND STABILISATION EFFECT OF GEOGRID LAYERS UNDER RAILWAY BALLAST}

\section{ABSTRACT}

This paper deals with the issue of the stabilization of railway track geometry. It details the published results in numerous international journals. Having analysed the cited publications the paper deals with a new research topic related to geogrid-reinforced railway ballast. A research team of the Department of Transport Infrastructure and Municipal Engineering at the Szechenyi Istvan University would like to continue working on this research topic.

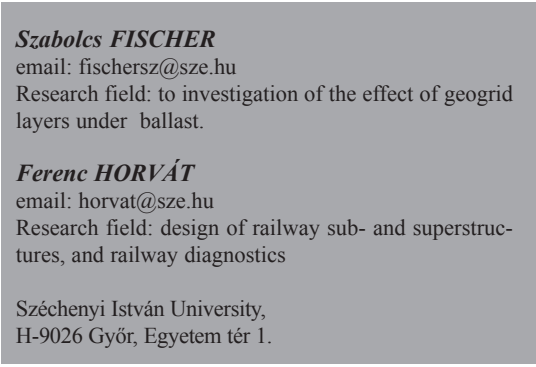

\section{KEY WORDS}

- ballast material,

- track deterioration,

- geogrid reinforcement,

- stabilization of railway track geometry.

\section{INTRODUCTION}

Geosynthethics have been used for soil reinforcement for many decades. They can compensate for some weak soil parameters; e.g., they ensure additional tensile and shear strength for soil structures. In this way soils with unsuitable geotechnical parameters can be used for the construction of steep slopes; with these types of soils very quick consolidation can also be achieved on bad quality subgrades. For example, geosynthetic-reinforced soils are also suitable for the construction of very good insulation and separation layers at waste dumps and help decrease the water permeability of soils (Szepesházi, 2008). Geogrids ensure additional tensile and shear strength for both granular and cohesive soils. Using this soil reinforcement, soils can bear not only pressure but also tensile force too, due to the longitudinal and tranversal ribs and junctions of a geogrid if there is adequate soil-geogrid interaction. This reinforced structure works similarly to reinforced concrete in which the concrete bears pressing forces, and reinforcing steel bars take up the tensile forces. Geogrids can be used for counteracting shear forces, but their use is limited because of the shear strength of geogrids.

Laboratory tests have been conducted, which are related to such use of geogrids in railway constructions where the subgrade/subsoil was not reinforced, but the bed-ballasted railway superstructure was. In these structures geogrids were placed under - and in some cases into - the ballast material. It was expected that the geogrid would clamp particles of ballast material at the bottom of the ballast; in this way the railway track would be floating in the ballast material and exposed to dynamic effects. For other vibrations the structure would be more resistant to the deformation of the tracks. This phenomenon is an interlocking effect (Figure 1), which can be imagined as the particles of the ballast material - like eggs in an egg carton - are wedged into the apertures of the geogrid. In this manner a quasistrong and relatively skidproof layer would be guaranteed for other particles lying above and interlocked into these particles.

The aim of this paper is to summarize the results of relevant international publications and, based on these, to give 


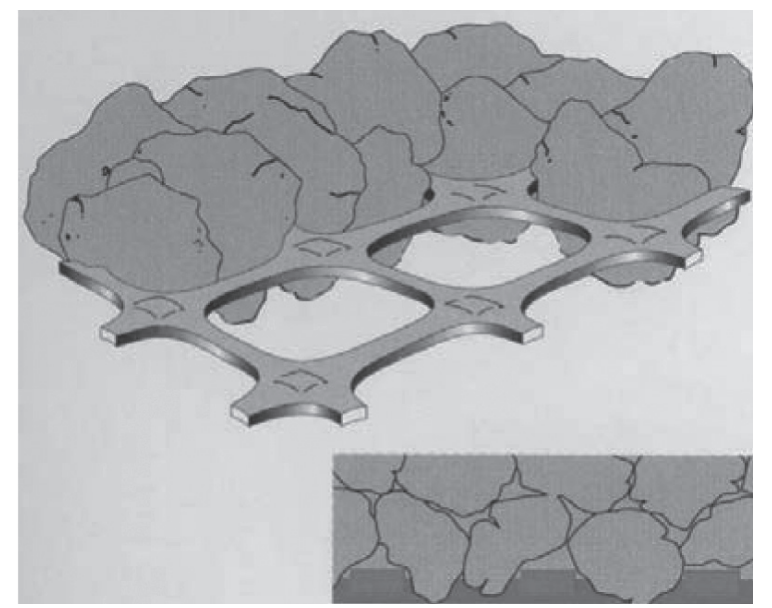

Fig. 1 The interlocking effect (Konietzky, et al., 2004.).

a comprehensive review, especially about laboratory tests of geogrid layers under ballast. The other goal of this paper is to formulate the target of the research on this topic at the Department of Transport Infrastructure and Municipal Engineering of Szechenyi Istvan University.

\section{PREVIOUS INTERNATIONAL RESEARCH}

International research teams have analysed geogrids for the reinforcement of railway superstructures in three different ways.

The first method was a laboratory test where full-scale or reducedscale assemblies were examined with cyclic and static loadings. In order to approximately and adequately determine the prospective benefits of the geogrids, reference measuremenrs should have been performed. The reference measurements were generally done with assemblies in which no geogrid reinforcement was laid; in this way the effect could be easily demonstrated with the differences in the results. Section 2.1 deals with this topic in detail.

The second method involved field tests where geogrids were built in railway lines carrying great volumes of traffic after a ballast replacement or cleaning, and tamping work. The beneficial effect of the geogrid can be demonstrated with the settlements in the function of the elapsed time from the setting in or the number of axles passed (gross-ton). Here, reference measurements were needed, which showed either the conditions before the laying of the geogrid in the same place or the conditions of a connected section where there was no geogrid-reinforcement.

The third method is very useful for decreasing the number of laboratory tests and decreasing the very high costs related to field trials; also, with this method the exactness of the measurements can be checked. This method was a computer-aided simulation with two possibilities: a simulation with the finite element method (FEM) or a simulation with the distinct element method (DEM).

This paper mostly deals with the results published in foreign literature and experience with laboratory tests connected to geogrid layers built under ballast; it also briefly introduces the computeraided simulations and field tests.

\subsection{Laboratory tests and their results}

Papers dealing with geogrid-reinforced railway ballast mostly publish the results of laboratory tests. Sections 2.1.1 and 2.1.2 summarize several parameters of these laboratory tests; Section 2.2 demonstrates their results.

\subsubsection{Material, loading and data recording parameters of laboratory tests}

The loadings applied during laboratory tests are an essential parameter. In the event of modest laboratory equipment, static loading can also be used, but static loading has mainly been used during geogrid pullout tests (with airbags built in the top section of a box), which is adequate for evaluating soil-geogrid interaction (Nejad and Small, 2005; Perkins and Edens, 2003; Shuwang, et al., 1998). Another possible use of static loadings is to complete the measurements with dynamic loading (Indraratna, et al., 2006; Indraratna, et al., 2007; Raymond, 2002; Raymond and Ismail, 2003). In the latter publications static loading had to be used to ensure the reproducibility of the measurements (Raymond, 2002). In particular, static loadings have to be applied to be able to notice the failure in the case of a static loading situation (Raymond and Ismail, 2003), and in the papers (Indraratna, et al., 2006; Indraratna, et al., 2007), horizontal static loadings were used on movable and loadable box walls. As a railway load is dynamic, much more precise results can be achieved if dynamic-cyclic loading is used. The magnitude of the cyclic loading depends on the size of the loading plate (because of the stress under the plate); the frequencyrange is regulated by standards, but an approximate value for this range can be calculated from the design vehicle's speed and axlebase. In the cited publications assemblies were examined at the 0-100 kN load-range and the 0.5-15 Hz frequency-range (Bathurst and Raymond, 1987; Brown, et al., 2006; Brown, et al., 2007; Indraratna, et al., 2006; Indraratna, et al., 2007; Matharu, 1994; Raymond, 2002; Raymond and Ismail, 2003; Shin, et al., 2002; Thom, 2009) (these values are not matching parameters, but are only extreme values).

One of the most important parameters for the assembled layers is the depth of the ballast bed. As the ballast bed's depth is approximately 250-350 $\mathrm{mm}$ in the railway tracks (under the sleeper's lower surface 
in the axle of the rail at the determinant side), the depth should be about the same value in any laboratory tests. This depth depends not only on the minimal technical depth of the tamping works but also on the adequate flexible load-bearing. The location of the geogrid layer is restricted, because the hammers of the tamping machines would catch the geogrid and damage the reinforced superstructure. In this respect the laboratory tests of papers (Raymond, 2002; Raymond and Ismail, 2003) are queriable, because micro geogrids were placed close to the bottom plane of the loading plate. Certainly the placement of more than one geogrid reinforcement layer into the ballast is also possible, but it is a very difficult and expensive undertaking with respect to construction and maintenance. The $4 \%$ cross-sloped subgrade plane could also be modelled in a laboratory, but it has not been mentioned in the cited publications. It is worth considering the setting in of the geogrid onto sandy gravel protection-strengthening layers, or onto sub-ballast (Brown, et al., 2006; Brown, et al., 2007; Indraratna, et al., 2006; Indraratna, et al., 2007; Shin, et al., 2002; Thom, 2009). To avoid the pushing of the ballast material particles into the subgrade, geotextiles should be applied (Shin, et al., 2002) in (Brown, et al., 2006; Brown, et al., 2007; Thom, 2009) combined geotextile-geogrid layers were used). The measurements will have a much wider spectrum and will be much more precise, if more types of parameters are applied in laboratory tests. This is related to Young's modulus of the modelled subgrade or subsoil (Brown, et al., 2006; Brown, et al., 2007; Raymond, 2002; Raymond and Ismail, 2003; Thom, 2009), and to the type of geogrid applied (Brown, et al., 2006; Brown, et al., 2007; Indraratna, et al., 2007; Raymond, 2002; Shuwang, et al., 1998; Thom, 2009) and the ballast bed's material (Indraratna, et al., 2006; Indraratna, et al., 2007; Nejad and Small, 2005; Raymond, 2002; Raymond and Ismail, 2003). These latter publications considered these three parameters with a minimum of two different values. The different Young's moduli were considered with open-cell neoprene rubber, closed-cell pure gum amber and other rubber sheets, as well as with soft soils. It should be noted that the case without a geogrid-reinforcement layer would be a good reference measurement. During the analysis of the ballast bed material, the grain size and dry-wet, fresh-recycled, clean-foul ballast materials should be considered. In the publications (Indraratna, et al., 2006; Indraratna, et al., 2007), all the above cases were considered except for the case of clean-foul ballast materials. Analysing the geogrids, the maximum tensile strength, the yield point strain, the stiffness of the ribs and junctions, the tensile strength at a $5 \%$ strain, as well as the aperture size are determining parameters; when changing these parameters, the behaviour of the geogrids can be qualified adequately and precisely. In the papers the required compaction methods are completely described for all the layers (the same number of compaction cycles, same compaction work, etc.).
The laboratory tests require exact measurement data, which can be received by precise measuring apparatus. These data are recorded digitally. Settlements during tests with static and cyclic loading and the pullout lengths at pullout tests were recorded with linear variable differential transducers (LVDT); the forces were recorded via load cells. The measurements should be repeated for a minimum of two to three times to avoid measuring errors, but such repetitions have not been mentioned in the cited publications. In the case of cyclic loading the number of cycles has to be registered, because the settlements can be evaluated by the function of the number of cycles.

\subsubsection{Build-up of loading structure and related parameters of the laboratory tests}

The condition of the laboratory should be determined as to whether the tests are done with full-scale (for ballast material and geogrids usable for railway tracks) or reduced scale assemblies. Laboratory tests with reduced scale assemblies are very questionable (Raymond, 2002; Raymond and Ismail, 2003) as they could provide inadequate results. As micro geogrids are not used in transport infrastructures, additional laboratory tests should be done. Railway tracks have significant dimensions in longitudinal and transversal directions too. In the case of a one-track railway line, the largest dimension of a ballast bed in a cross direction is approximately 4.5-5.5 m; therefore, large laboratory assemblies have to be built. The most precise and accurate results can be achieved with laboratory tests of a full-scale railway track assembly (Bathurst and Raymond, 1987; Matharu, 1994; Thom, 2009) (Figures 2-3). One paper (Shin, et al., 2002), where the box was built with $1400 \times 1000 \times 2000 \mathrm{~mm}$ dimensions in its length, width and height respectively, should be mentioned.

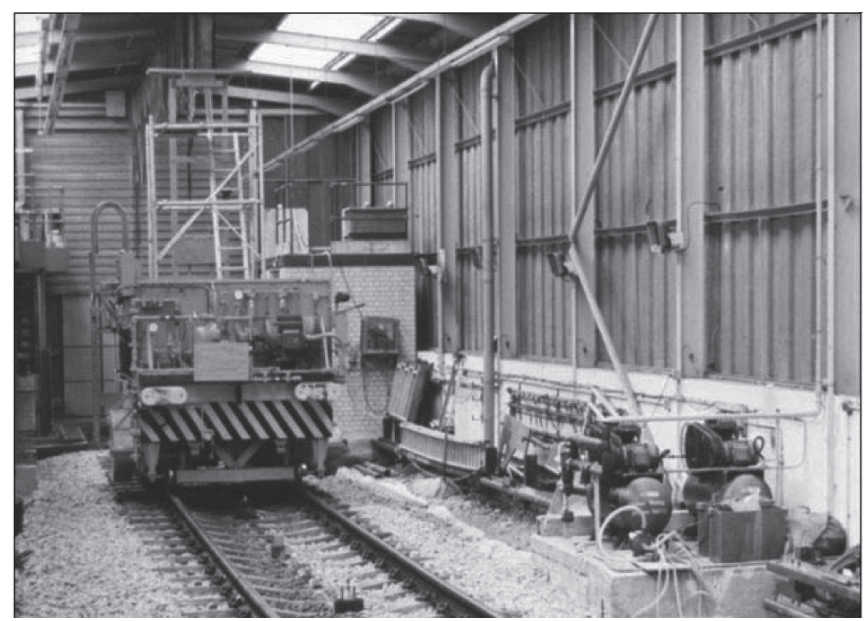

Fig. 2 Modelling a full-scale railway track assembly (Matharu, 1994). 


\section{IDYALS JOUSSIAL \\ 0)

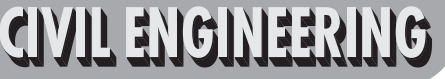

2011/3 PAGES $22-30$

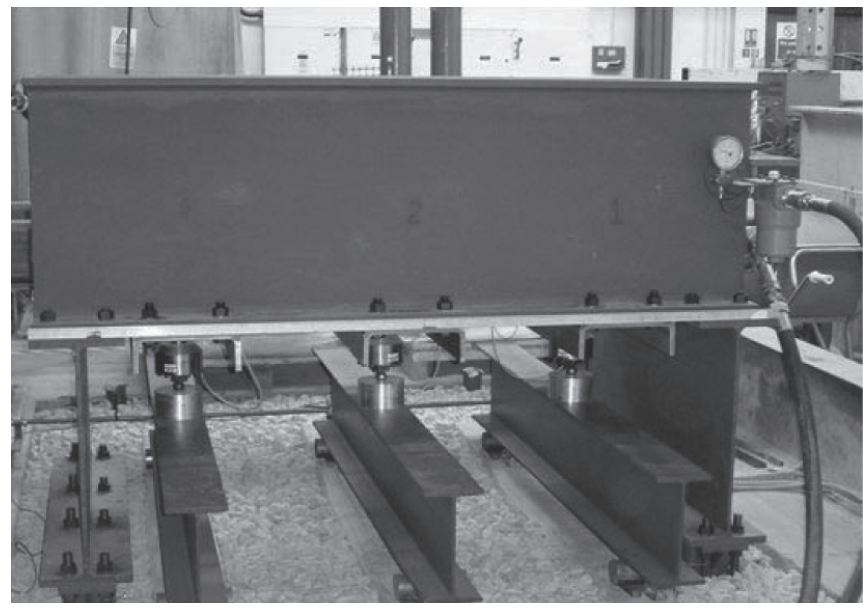

Fig. 3 Cyclic loading equipment with a full-scale railway track assembly (Thom, 2009).

To reduce the friction between the ballast material particles and the test box, care should be taken that the box is significantly smaller than the width of the ballast bed in actual railway tracks. In all honesty, it is not a simulation of real conditions, but it is much better than a case without any friction reduction. This solution should mainly be applied during geogrid pullout tests (Nejad and Small, 2005; Perkins and Edens, 2003), because owing to the particle jam at the boxwalls, much higher (false) pullout forces can be measured. Friction reduction methods have also been mentioned during laboratory tests which modelled a reinforced railway superstructure (Brown, et al., 2006; Brown, et al., 2007; Thom, 2009).

The loading plates should have such dimensions that the stress derived from the test loading applied and the area of the loading plate will be approximately equal to the stress derived from the wheel load and the dimensions of the sleeper. The loading plates should be made of steel or concrete for rigid behaviour, thus avoiding their influence on the results of the tests. Air bags were applied in (Nejad and Small, 2005; Perkins and Edens, 2003; Shuwang, et al., 1998); aluminium plate was used in (Raymond, 2002; Raymond and Ismail, 2003); a steel loading plate was applied in (Brown, et al., 2006, Brown, et al., 2007, Thom, 2009); a wooden sleeper was used in (Indraratna, et al., 2006; Indraratna, et al., 2007), and a concrete sleeper was applied in (Matharu, 1994; Thom, 2009). As the slumping of the ballast bed's shoulders due to the vibrating effect of the railway load also generates and intensifies the deterioration process of a railway track, this topic should be highlighted. The simulation of a ballast bed's shoulder is difficult because full-scale assemblies have to be made, and cyclic loading should be applied. In the case of boxes with a full-height wall, the simulation of the slumping of the ballast bed's shoulder is impossible

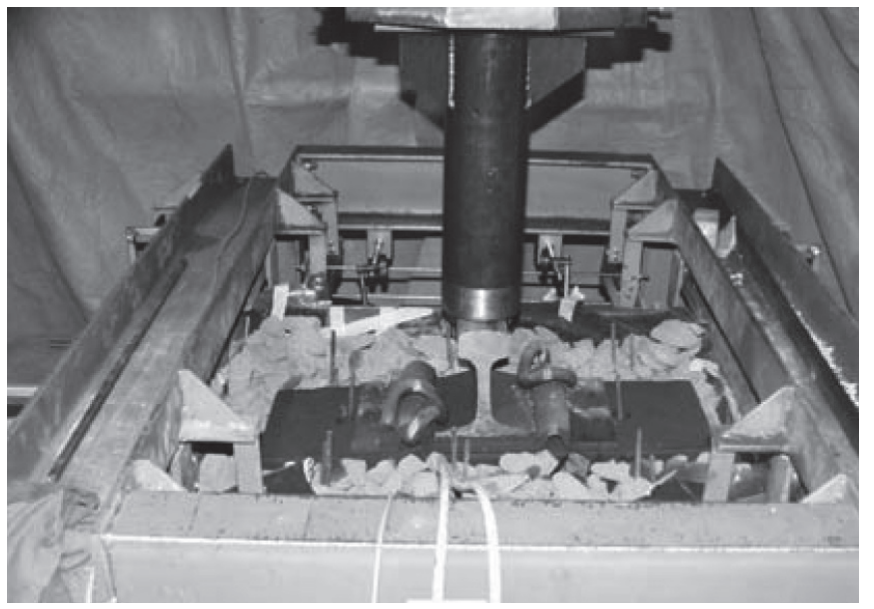

Fig. 4 Triaxial test with full-height wall boxes (Indraratna, et al., 2007).

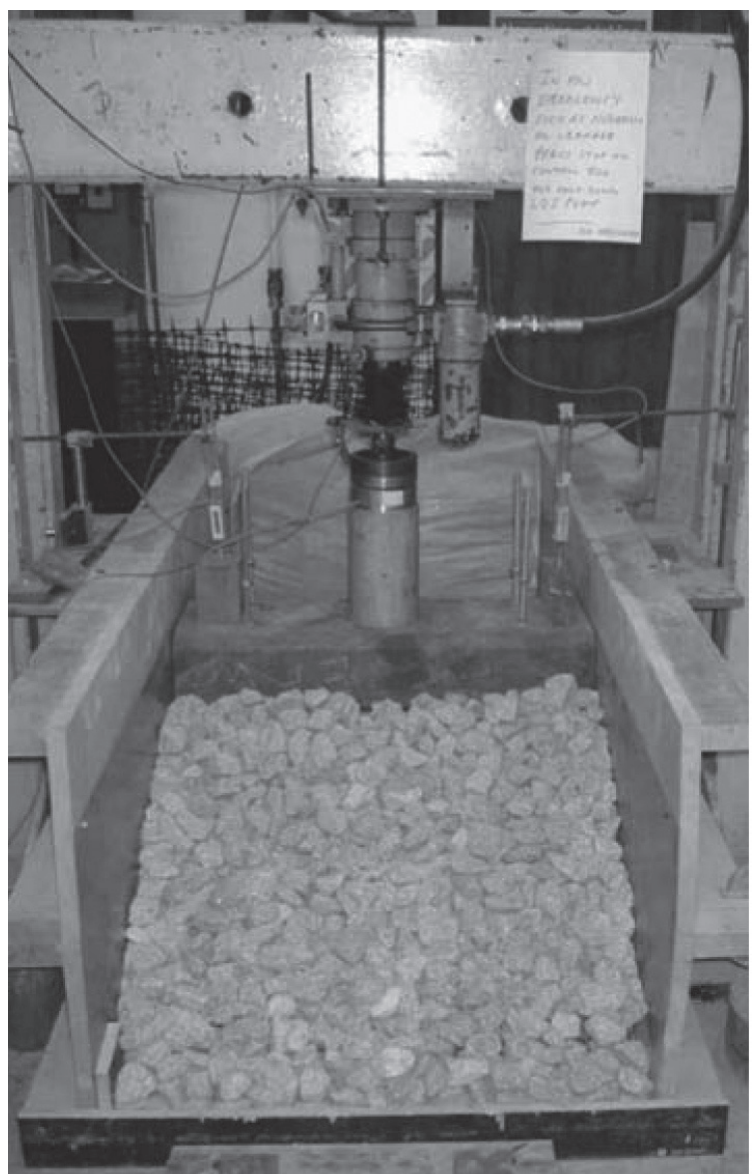

Fig. 5 Laboratory test where the ballast shoulder was built up (Brown, et al., 2007). 
(Indraratna, et al., 2006; Indraratna, et al., 2007; Raymond, 2002; Raymond and Ismail, 2003; Shin, et al., 2002) (Figure 4). This is good as a kind of approximation, but actual conditions cannot be considered with this method. In the papers (Bathurst and Raymond, 1987; Brown, et al., 2006; Brown, et al., 2007; Matharu, 1994; Thom, 2009), the ballast bed's shoulder was built up; therefore, the results show the track stabilization effect of geogrid layers under ballast more adequately (Figure 5).

\subsubsection{Results of the laboratory tests}

It has been mentioned that in the papers (Raymond, 2002; Raymond and Ismail, 2003), reduced scale assemblies were used for the laboratory tests. Although the results of these measurements are queriable, it has to be highlighted that in (Raymond, 2002), a significant reduction of settlement (50\% and $13-30 \%)$ could be achieved with both rounded (uncrushed) and crushed particles. The aggregate crushing was decreased due to the geogrid layers. The most unbelievable result is that the most effective reinforcement was measured close to the loading plate (at a very small depth) (Raymond and Ismail, 2003). This setting is impossible because of the technology; in other respects it is true that the interlocking effect has the largest value on the plane of a geogrid layer, but for this you need enough soil covering the depth. In the authors' view there were not enough soil depths in the measurements of the paper (Raymond and Ismail, 2003).

The measurements described in (Shin, et al., 2002) showed that the largest reduction of settlements could be obtained with three geogrid layers (one would be between the subbase and the subgrade soil; one would be in the subbase, and one would be under the subballast). In this paper, a huge measuring box $(1400 \times 1000 \times 2000 \mathrm{~mm})$, layers assembled at their full height, an actual railway sleeper and cyclic loading were used. The most effective forming was received in the case of combined geotextile-geogrid layers, which were set in between the subbase and the subgrade soil (the total settlement reduction was $33 \%$ ).

The widest range of the research can be found in (Indraratna, et al., 2006) and (Indraratna, et al., 2007). The results of these papers show that the lowest plastic settlements were obtained when using fresh ballast materials with geogrid layers, and the largest plastic settlement were achieved with recycled ballast materials without a geogrid reinforcement. There were positive effects of the geocomposite and geotextile reinforcements to reduce settlements of the recycled and fresh ballast materials, but in the geocomposite reinforcement, only the geogrid is the working part. After the initial large values (until 100,000 cycles) in the settlements and in the lateral and vertical strains of the ballast, these values consolidated. The lateral strains of the ballast were reduced in the case of fresh, dry ballast materials, but this kind of positive effect can also be achieved in the case of recycled and wet or dry ballast materials using a geotextile or a geocomposite.

Such positive reinforcement and stabilization results were obtained during the laboratory tests using full-scale assemblies (Bathurst and Raymond, 1987; Brown, et al., 2006; Brown, et al., 2007; Matharu, 1994; Thom, 2009). According to the results of (Bathurst and Raymond, 1987), at 39\% of CBR-value 4.75 times, and at $1 \%$ of CBR-value 4.9 times, more cycles generated $25 \mathrm{~mm}$ plastic settlements in the case of a Tensar geogrid reinforcement than without it. (Matharu, 1994) showed that geogrid-reinforced railway ballast has a positive effect on the retardation of the deterioration process. The most important result in (Brown, et al., 2006; Brown, et al., 2007; Thom, 2009) is that the most effective plastic settlement reduction was received (considering 30,000 cycles and $50 \mathrm{~mm}$ crushed particles) with geogrid apertures 1.4 times larger than the particle size (Figures 6-7). For the best reinforcement, the stiffness value of the geogrid was $1050-1150 \mathrm{MN} / \mathrm{m}$, considering 30,000 cycles. The slump of the ballast bed's shoulder was exactly modelled in (Bathurst and Raymond, 1987; Brown, et al., 2006; Brown, et al., 2007; Matharu, 1994; Thom, 2009).

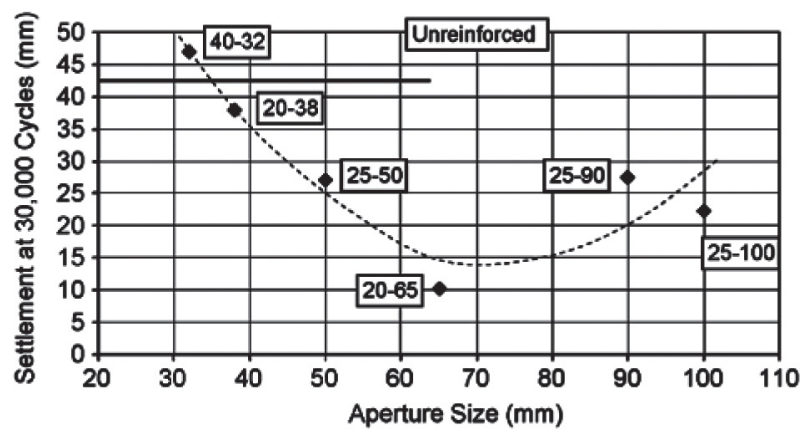

Fig. 6 Influence of the aperture size on settlements (Brown, et al., 2007).

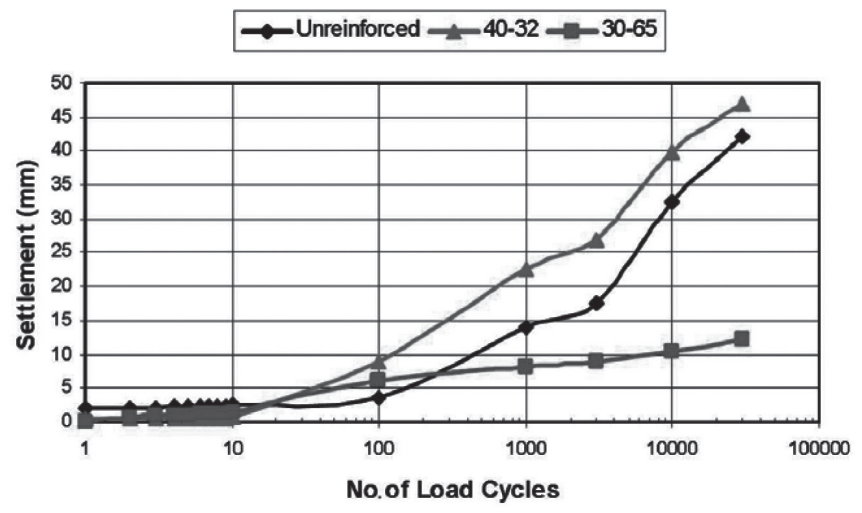

Fig. 7 Settlements vs. number of load cycles (Brown, et al., 2006). 


\section{IDYALS JOUSSIAL

In the cited papers related to geogrid pullout tests (Nejad and Small, 2005; Perkins and Edens, 2003; Shuwang, et al., 1998), there are no new scientific results. The results of the measurements and conclusions (residual shear strength, etc.) can be found in technical books (Szepesházi, 2008). New research results can be found in (Perkins and Edens, 2003): in testing the pullout behaviour of a geogrid, a linear elastic model gives adequate results; therefore, the more difficult bounding surface plasticity model need not be used.

\subsection{Field tests}

Tests mostly conducted in Hungary and abroad have been reported in the geogrid manufacturers' product guides (e.g., Tensar, Naue Fasertechnik, Viacon, etc.). This topic is just briefly mentioned in this paper. The field tests are summarized in (Raymond, 2002; Raymond and Ismail, 2003) (Figure 8), while (Brown, et al., 2006; Brown, et al., 2007; Thom, 2009) give more detailed descriptions of them. It can be undeniably agreed that geogrid reinforcements under the ballast have a beneficial effect on the geometric stabilization of a railway track. Using an adequate geogrid type, the time interval between tamping works can be lengthened to 2-2.5 times than without the geogrid layer; therefore, it is a very cost-effective and beneficial solution, because the additional construction costs of geogrids are much lower than the total construction costs. The setting of geogrid reinforcement layers is suggested not only for new railway tracks but also for old, distorted tracks. Considering the additional cost of geogrid layers and the increased maintenance time interval, the rate of return can be calculated; thus, remarkable national economic benefits can also be mentioned when using them.

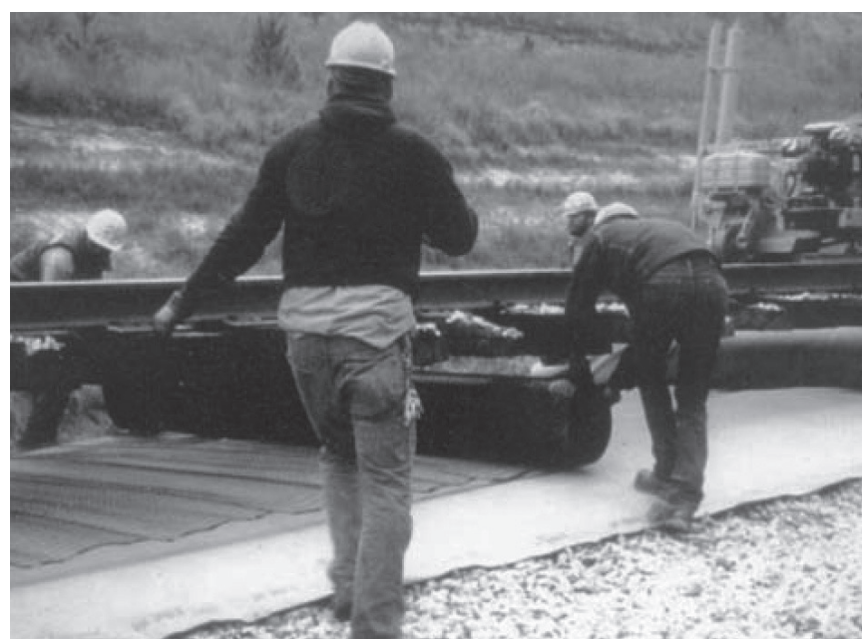

Fig. 8 Installation of a geogrid layer under a railway track ballast (Raymond, 2002).

\subsection{A short introduction to the computer-aided simulations}

Geogrid-reinforced railway superstructures can be simulated with finite element methods or distinct element methods in two or three dimensions.

With the finite element method the subsoil, geogrid(s), railway ballast, loading plate and sleeper are modelled as different elements, which are considered either as distinct "big" elements or are divided into a finite number of parts by generating an inner net which has a finite number of nodes. Next, the material models, connection properties, etc., should be defined and, considering these parameters, numerical methods have to be used or differential equations have to be solved to achieve results.

In the case of distinct element methods, the ballast material particles are modelled with defined diameter balls or clumps (= complex, multiple balls). In this method every ball is a distinct or discrete element (Figure 9). The assembly of the balls is usually generated with the help of a particle size distribution for modelling railway ballast, but for some examples, random generation is also acceptable. There are distinct element numerical softwares (PFC, OVAL, etc.), which consider particles as rigid balls, but other programs can also be used which calculate with deformable particles (UDEC). In the first group, the material properties are considered with the contacts; in the second group stress-strain functions are required for the calculations. Modelling of the geogrids can be applied with both types (Bagi, 2007).

Distinct element methods provide more precise results than finite element methods, but for DEM, prior laboratory tests are needed. The distinct element model has to be refined with the results of the laboratory tests. The resulting computer model should behave the same as the laboratory model. If it is ensured, simulating further measurements is much simpler than time-consuming and expensive laboratory and field tests. Because of the limited size of this paper, (Bussert, 2009; Konietzky, et al., 2004) and (McDowell, et al., 2006) are just mentioned, the topics of which are related to DEM simulations of geogrid-reinforced railway ballast.
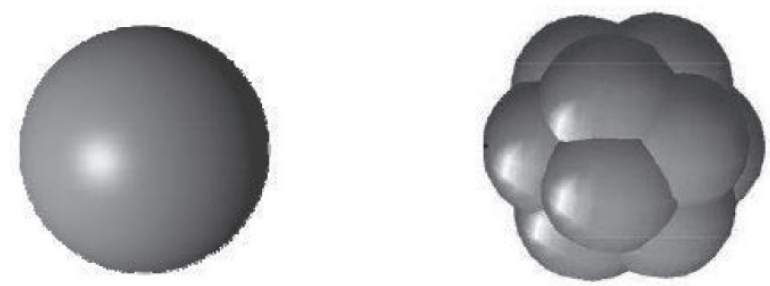

Fig. 9 Ball and clump elements in $3 D$. 


\section{FURTHER RESEARCH IDEAS}

\subsection{Multi-level shear box tests}

The authors attempted to approximate the effect of geogrid layers under railway ballast material by measuring settlements due to vertical and horizontal static and dynamic loadings, the interaction between the ballast material and geogrid, as well as the reduction in aggregate crushing. In the case of ballast bedded railway superstructures, the depth of the ballast material is a determining parameter. The geogrid reinforcement layer under the ballast has an additional clamping effect for the ballast material only up to a height " $h$ ". In reviewing the laboratory tests published in international papers, it was found that no tests were completed to determine the precise effect of interlocking in a vertical direction. In (Konietzky, et al., 2004; McDowell, et al., 2006), the geogrid pullout tests were modelled with computer-aided simulations; the result was that in the case of a specific ballast material and geogrid, the interlocking effect of the geogrid extends approximately to $\mathrm{a}+/-10 \mathrm{~cm}$ zone. Our university research team plans to do laboratory tests with a multi-level shear box to examine the change in the interlocking effect in the function of the vertical distance upwards from the geogrid's plane, which has also been missing from the international research topics too. The schematic drawing of the multi-level shear box is shown in Figure 10.

During the laboratory tests, subgrades with three different Young's moduli (e.g., 9, 15 and $25 \mathrm{MPa}$ ), fresh and recycled ballast materials, vertical loadings with three different values, and three different types of geogrids will be considered, which means at least 54 cases. The vertical function of the interlocking effect of the geogrid can be determined by measuring the resistance forces $\left(\mathrm{F}_{\mathrm{H}}\right)$ during the horizontal shearing at four shear planes. Considering the

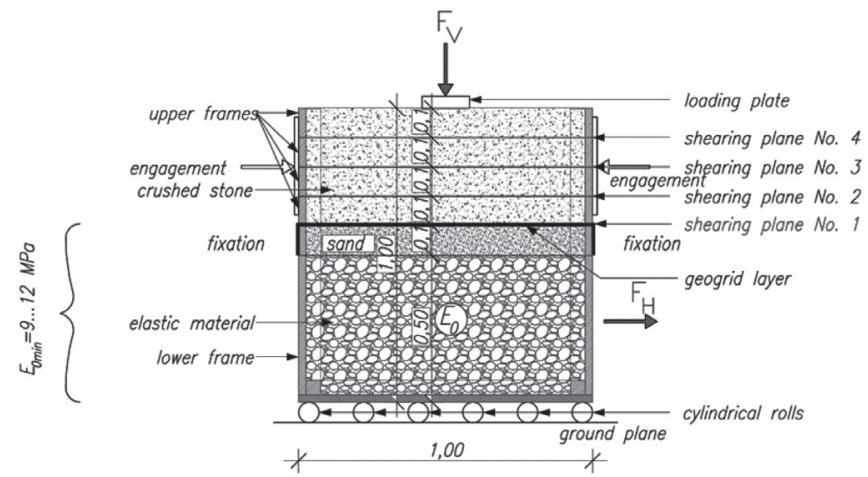

Fig. 10 Schematic drawing of a multi-level shear box (shearing at shear plane No. 1). four shear planes, at least 216 measurements will have to be done, which is very time-consuming work. The same compactness of the ballast will be guaranteed to the produce same compaction work (same layer depths, same tools, same compaction cycles, etc.). The Young's modulus of the material in the lower frame, the particle size distribution, the values of the vertical and horizontal loadings, the lateral displacement of the lower frame of the shear box, as well as the settlements will have to be measured and recorded. There will be small windows on the side (parallel to the shearing direction) of the upper frames and in the frame under the geogrid layer in order to monitor the particles' movements.

\subsection{Field tests}

Because during laboratory tests some approximations have to be applied for modelling the actual conditions, field tests are also needed. For these measurements test sections will have to be built on railway lines carrying high volumes of traffic. The test sections will have to contain sections with and without geogrid reinforcements in order to have reference measurements. It is suggested that geogrid layers be set into existing tracks during ballast cleaning work. During the installation the vertical and horizontal position of the rails should be measured at every fifth sleeper with a $0.1 \mathrm{~mm}$ accuracy.

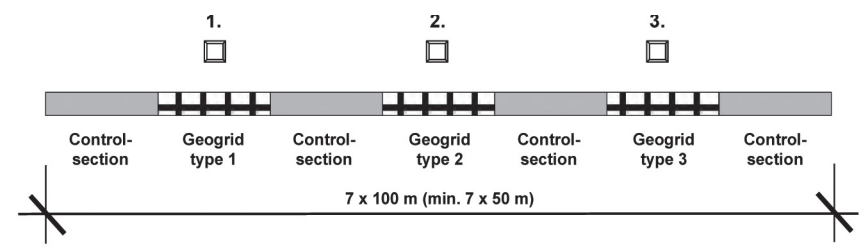

1., 2., 3. = survey columns

Fig. 11 Schematic drawing of the field tests.

For these measurements, special survey columns or reference screws in the overhead line poles will have to be applied (Figure 11). At (previously) defined time intervals (1, 2, 6, 12, 18, 24 months) repeated geodesic measuring will have to be done. Settlements that occur in geogrid-reinforced sections with different types of geogrids can be compared to each other and to the settlements that occur in sections without a geogrid reinforcement. In this way the railway track stabilisation effect of the geogrids and the savings due to the geogrid reinforcement can be determined. The functions of the track deformations (horizontal and vertical) and the track distortion as a function of the through-rolled gross ton or the number of the through-rolled axles can be calculated. The minimal required depth of the ballast can be determined from the laboratory tests. 


\subsection{DEM simulation}

With the DEM simulations published in the papers (Bussert, 2009; Konietzky, et al., 2004; McDowell, et al., 2006), the common behaviour of the geogrid layer and the ballast material particles can be effectively determined. For this the results of the laboratory tests have to be available. These data will be used in the PFC3D (Particle Flow Code in three dimensions), which is a software developed by ITASCA Consulting Group Inc. Our research team would like to verify the time-consuming and expensive laboratory measurements with DEM modelling, and we would like to complete these measurements with simple calculations. The team wants to use clumps for the calculations. If a great deal of cases (geogrid types and numbers of layers, contact properties of the particles, etc.) are considered, more precise results can be obtained from the geogridreinforced track using the DEM simulation. The movements of the particles monitored with digital cameras through the small windows can be reproduced with the PFC3D and compared to each other.

\section{SUMMARY}

The geometric stabilization effect of a railway track for geogrid layers built in under a ballast can be verified with laboratory tests, field trials and computer-aided simulations. In the international publications there are good practices and bad examples too. All the data dealing with laboratory and field measurements, as well as DEM simulations, were taken from the international literature. In (Raymond, 2002; Raymond and Ismail, 2003), reduced scale assemblies used for laboratory tests are discussed the results of which are very queriable; however, rounded (uncrushed) particles are generally worse for railway ballast aggregates than crushed ones. (Raymond and Ismail, 2003) achieved a more significant reduction in settlement with rounded particles $(50 \%)$ than with crushed ones (13-30\%). (Raymond and Ismail, 2003) did not consider the technical requirements (ballast depth over geogrids), but it is one of the most important factors with respect to construction because of the maintenance work (tamping depth).

Numerous papers have pointed out the fact that track settlements are able to be reduced by geogrid reinforcements. Fresh and recycled ballast materials and wet and dry aggregates with geogrids and/ or geocomposites as well as without geosynthetics (Indraratna, et al., 2006; Indraratna, et al., 2007) were considered too. Laboratory tests made with full-scale assemblies (Bathurst and Raymond,
1987; Brown, et al., 2006; Brown, et al., 2007; Matharu, 1994; Thom, 2009) demonstrated similarly good results due to geogrid reinforcements. The most important result in (Brown, et al., 2006; Brown, et al., 2007; Thom, 2009) is that the most effective plastic settlement reduction was achieved (considering 30,000 cycles and $50 \mathrm{~mm}$ crushed particles) with a geogrid aperture 1.4 times larger than the particle size. The slump of the ballast bed's shoulder has also been modelled (Bathurst and Raymond, 1987; Brown, et al., 2006; Brown, et al., 2007; Matharu, 1994; Thom, 2009).

The results from field tests are mostly published in geogrid manufacturers' product guides (e.g., Tensar, Naue Fasertechnik, Viacon, etc.), but there are also papers (Raymond, 2002; Raymond and Ismail, 2003; Brown, et al., 2006; Brown, et al., 2007; Thom, 2009) dealing with this topic. These cited publications summarized the fact that tracks constructed with geogrid-reinforced railway ballast provide better resistance against settlements. It can be undeniably agreed that geogrid reinforcements under a ballast bed have a beneficial effect on the geometric stabilization of a railway track.

DEM modelling is adequate for simulating geogrid-reinforced railway ballast. Geogrid pullout tests were modelled by PFC3D in (Konietzky, et al., 2004; McDowell, et al., 2006). These papers determined that in the case of specific ballast material and geogrids, the interlocking effect of the geogrid extends approximately to a $+/$ $10 \mathrm{~cm}$ zone.

The interlocking effect's vertical function has not been exactly clarified and published. The research team of the Department of Transport Infrastructure and Municipal Engineering at Szechenyi Istvan University would like to study this research topic. A multilevel shear box will be used; field tests will be performed with numerous geogrid types; and DEM simulations will have to be used for this research. Cost-benefit calculations will also be applied.

\section{Acknowledgements}

The authors' research is sponsored by Hungarian Railways, Tensar International Ltd., Gradex Ltd., Naue Fasertechnik Ltd., as well as Viacon Hungary Ltd; and supported by TAMOP-4.2.1/B-09/1/ KONV-2010-0003: Mobility and Environment. The Project is supported by the EU and co-financed by the European Social Fund. The authors would like to thank Dénes Szekeres (Hungarian Railway) for his scientific and technical help, and to Katalin Koncz (civil engineering student) for her help in the processing of literature. 


\section{REFERENCES}

[1] Bagi, K. (2007): Diszkrét elemek módszere (The distinct element method), university course book, Budapest University of Technology and Economics, Department of Structural Mechanics, Budapest, 2007, p. 73 (in Hungarian)

[2] Bathurst, R. J., Raymond, G. P. (1987): Geogrid reinforcement of ballasted track, Transportation Research Record No. 1153, 1987, pp. 8-14

[3] Brown, S. F., Thom, N. H., Kwan, J. (2006): Optimising the geogrid reinforcement of rail track ballast, conference issue, Railfound Conference, Birmingham, 2006, pp. 346-354

[4] Brown, S. F., Kwan, J., Thom, N. H. (2007): Identifying the key parameters that influence geogrid reinforcement of railway ballast, Geotextiles and Geomembranes, Vol. 25, 2007, pp. 326-335

[5] Bussert, F. (2009): Recent research into the actual behaviour of geogrids in reinforced soil, conference representation, Jubilee Symposium on Polymer Geogrid Reinforcement, September 8, 2009, London

[6] Indraratna, B., Shahin, M., Rujikiatkamjorn, C., Christie, D. (2006): Stabilisation of ballasted rail tracks and underlying soft formation soils with geosynthetic grids and drains, ASCE Special Geotechnical Publication No. 152, Proceedings of GeoShanghai 2006, 2-4 June, 2006, Shanghai, China, pp. 143-152

[7] Indraratna, B. Shahin, M. A., Salim, W. (2007): Stabilisation of granular media and formation soil using geosynthetics with special reference to railway engineering, Journal of Ground Improvement, Vol. 11, No. 1, 2007, pp. 27-44

[8] Konietzky, H., Te Kamp, L., Groeger, T., Jenner, C. (2004): Use of DEM to model the interlocking effect of geogrids under static and cyclic loading, Numerical Modeling in Micromechanics Via Particle Methods - 2004 (Proceedings of the 2nd International PFC Symposium, October 2004, Kyoto, Japan), Y. Shimizu, et al., eds. Leiden: Balkema, 2004, pp. 3-11
[9] McDowell, G. R., Konietzky, H., Jenner, C., Harireche, O., Brown, S. F., Thom, N. H. (2006): Discrete element modelling of geogrid-reinforced aggregates, Geotechnical engineering, Vol. 159, No. 1, 2006, pp. 35-48

[10] Matharu, M. (1994): Geogrids cut ballast settlement rate on soft substructures, Railway Gazette International, Vol. 3, March 1994, pp. 165-166

[11] Nejad, F. M., Small, J. C. (2005): Pullout behaviour of geogrids, Iranian Journal of Science \& Technology, Transaction B, Engineering, Vol. 29, No. B3, 2005, pp. 301-310

[12] Perkins S. W., Edens M. Q. (2003): Finite element modeling of a geosynthetic pullout test, Geotechnical and Geological Engineering, Vol. 21, 2003, pp. 357-375

[13] Raymond, G. P. (2002): Reinforced ballast bahaviour subjected to repeated load, Geotextiles and Geomembranes, Vol. 20, 2002, pp. 39-61

[14] Raymond G., Ismail, I. (2003): The effect of geogrid reinforcement on unbound aggregates, Geotextiles and Geomembranes, Vol. 21, 2003, pp. 355-380

[15] Shin, E. C., Kim, D. H., Das, B. M. (2002): Geogrid-reinforced railroad bed settlement due to cyclic load, Geotechnical and Geological Engineering, Vol. 20, 2002, pp. 261-271

[16] Shuwang, Y., Shouzhong, F., Barr, B. (1998): Finite-element modelling of soil-geogrid interaction dealing with the pullout behaviour of geogrids, Acta Mechanica Sinica (English Series), Vol. 14, No. 4, Nov. 1998, pp. 371-382

[17] Szepesházi, R. (2008): Geotechnika (Geotechnics), university course book, Szechenyi Istvan University, Gyor, 2008, p. 187 (in Hungarian)

[18] Thom, N. H. (2009): Rail trafficing testing, conference representation, Jubilee Symposium on Polymer Geogrid Reinforcement, September 8, 2009, London 